\title{
SMART GRID: THE FUTURE OF THE ELECTRIC ENERGY TRANSMISSION AND DISTRIBUTION SYSTEM
}

\author{
Taanees Zargar \\ Research Scholar \\ Department of electrical engineering \\ SSM College of Engineering \\ Parihaspora Pattan, J\&K India
}

\author{
${ }^{1}$ Ishtiyaq Shafi Rafiqi, ${ }^{2}$ Adfar Majid, ${ }^{3}$ Arshid Ali \\ ${ }^{1 \& 2}$ Associate Professor, ${ }^{3}$ Assistant Professor \\ Department of Electrical Engineering \\ SSM College of Engineering \\ Parihaspora, Pattan, J\&K India
}

\begin{abstract}
The contemporary epoch is under a serious energy crisis. With increasing energy demands and exhausting energy resources, this catastrophe is difficult to get through. Sustainable and efficient utilization of energy resources can pave the way to a world with, energy for all and energy forever. Electrical energy, the most widely used form of energy, if used efficiently and sustainably can ease the overall energy crunch. This paper gives an insight into how the adaptation of SMART GRID TECHNOLOGY can consequently relieve the pressure on energy demand and secure the energy resources for the future
\end{abstract}

KEYWORDS - Energy Efficiency, Energy Sustainability, Smart Grid, Smart Meters, Distributed Renewable Generation

\section{INTRODUCTION}

The current era witnesses a huge spike in the energy demand, largely to meet up the industrial requirements and growing domestic needs. It has been merely 10 years since when co-operations began to think that energy is expensive, until then the notion, energy is a tool worth any cost, was all that mattered. Among all the forms of energy, electric energy is used widely, thus an efficient use of electric energy can counter the global energy crisis. The transition from traditional electric grids to SMART GRIDS will have a tremendous impact on electric energy utilization. SMART GRID promotes automatic, identification of energy fluctuations and power delivery restorations, thus leads to efficient use of electric energy. Simultaneously, saving energy for the future is the need of the hour as growth in any sector without being sustainable would hardly fetch us anything for the future. Energy sustainability has a strong coupling with environmental sustainability. The energy sources are a gift from the environment and can be reserved for future generations only when the environment is rescued from degrading.
Environmental degradation will cause consequential damages to sustainable energy developments. Global environmental degradation is due to the greenhouse effect caused by greenhouse gases among which carbon dioxide (CO2) is the principal greenhouse gas (GHG). As the matter of fact, about $40 \%$ of $\mathrm{CO} 2$ emission is from electric power generation. Reducing $\mathrm{CO} 2$ emissions is a challenge that can be overcome by implementing SMART GRID TECHNOLOGY, which encourages the use of clean energy. SMART GRID uses green energy sources for power generation. This paper shall discuss a route to an energyefficient world and sustainable energy development through SMART GRID TECHNOLOGY.

\section{ENERGY EFFICIENCY THROUGH SMART GRID}

The world energy demand is prophesied to increase by $37 \%$ by the year 2040 . The International Energy Agency (IAE) admits that energy efficiency plays a critical role in relieving the pressure on the energy supply. Energy efficiency suggests that the same task should be performed using less energy that would result in the removal of energy waste. Electric energy, being the most widely used energy form and an important medium of other energy utilization, will also face a shortfall due to the brawl between supply and demand. To hold out against the energy crisis, efficient use of energy is essential. The present world is looking forward to substituting the traditional power grids infrastructure with more efficient and technologically advanced and smarter grids. With the help of smart grid technology and the active participation of consumers, the electric utility industry can manage the rising power demand, particularly during peak hours. Smart grid comes up with a platform that aims at the exchange of information between the electric utility industry and consumers. Smart grid technology incorporates SMART GENERATION, SMART 
TRANSMISSION, and SMART DISTRIBUTION as its main features.

1. Smart grid uses green and renewable energy sources for the production of electric power leading to lower power generation costs: SMART GENERATION

One of the key advantages of the smart grid is that it uses green energy sources for power generation, that are renewable and are less expensive such as wind and solar energies. While a decade ago, solar energy was expensive for utilization, it has now cheapened at a searing pace with about a $90 \%$ reduction in its cost. Concurrently, the last decade observed a reduction in wind energy costs as well. The lifetime cost of a new wind farm shrank to $71 \%$ in the last 10 years. Latest technological advancements have powered the rise of renewable sources as feasible general-purpose energy sources. Since sunshine and wind are available for free the cost of extraction has reduced variably with the advent of technological advancements and industrial growth. On contrary, the fossil fuels can't prove to be that efficient as the extraction of fossil fuels require a lot of mining-related operations. Thus, the use of green and renewable energy sources for the production of electric power would lead to lower power generation costs in smart grids.

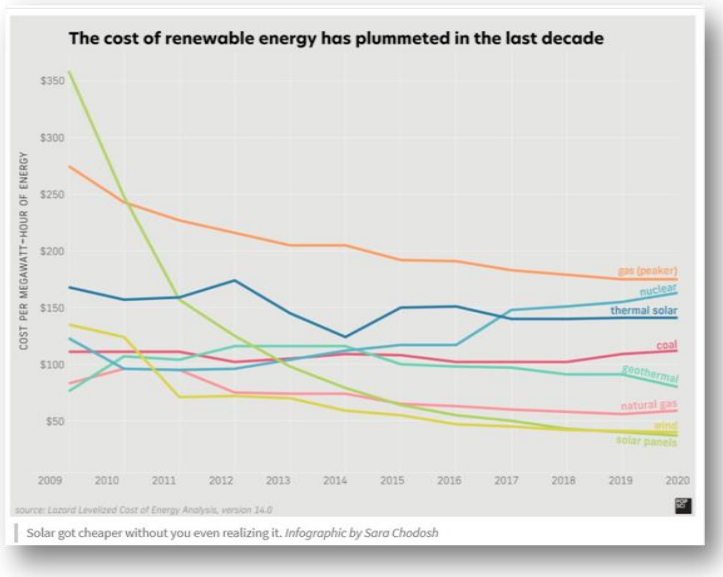

Fig 2:Cost of renewable energy during the last decade

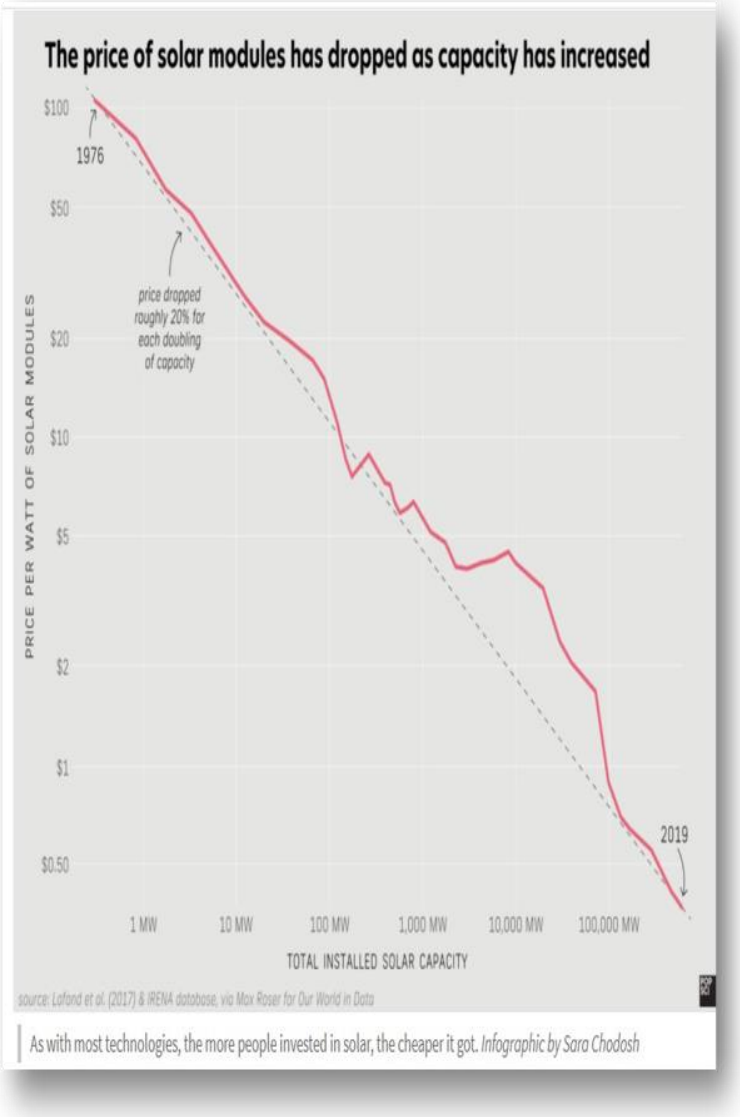

Fig1:Price of solar modules with respect to installed solar capacity

2. Smart grid optimally adjusts the power transmission at low cost and high quality: SMART TRANSMISSION

The traditional grids use additional power plants that are often less efficient to deliver power at peak hours as a result electricity becomes more costly during peak hours. Unlike traditional grids, the smart grid gives a detailed insight into electric power consumption in real-time. Utilities delay the electricity usage away from peak hours and make the appliances and devices work at times other than peak hours, thus reducing the operating cost. The amount of electricity generated and consumed should be equal at every instant of time and effective use of the smart grid can precisely manage the production and consumption of electricity thus reducing the need to fire up the costly secondary power plants. During transmission, electricity flows from the base station to consumers but the smart grid allows transmission of electricity along with the real-time pricing information, thus making consumers aware of the price at which they can consume the power. This regulates the consumption as per prices. The process of sending info in a smart grid is carried out by wireless sensors. These sensors are attached to transmission lines wherefrom it sends pricing 
information to the consumers and also senses the condition of blackout. In case of a blackout, the smart grid quickly resorts to another network to provide an uninterrupted power supply to affected houses. Smart grid sensors also assist remote monitoring of equipment like transformers and management of resources on the demand side.

3. Smart grid fosters automatic identification of energy fluctuations and power delivery restorations: SMART DISTRIBUTION

Smart grid has Information Communication Technology (ICT) for gathering information about consumption from the consumers, thus enabling even distribution of electricity. Distribution intelligence is another smart feature of the smart grid that can foresee and balance the electricity utilization with coordination of consumers, thus leading to ease the power delivery cost. ICT provides tariff information and collects information about the status of the grid regarding faults, power quality, etc. By introducing Automatic Metering Infrastructure (AMI) in the smart grid technology an efficient bi-directional flow of electricity and information can be carried out. The AMI not only conveys information from smart meters to utilities but also transfers information about peak demands and the cost of power consumption to consumers so that consumers can utilize electricity with intelligence and shift peak loads to times other than peak hours. AMI comprises of Home Area Network (HAN), Neighbourhood Area Network (NAN), Wide Area Network (WAN). AMI entails the installation of SMART METERS at consumer premises that analyzes the electricity consumption of the consumers and thus convey this information to the electric utility industry. For better control of the utility center, a systematic analysis of data is essential, and this is carried out by smart meters. The Smart meter is responsible for the collection, communication, and storage of data. Smart meters come up with the advantages like identification of power theft, outage detection, real-time pricing, abandoning meter data tempering.

\section{ENERGY SUSTAINABILITY THROUGH SMART GRID}

Energy sustainability intends at addressing the demand of current generations without affecting the availability of sources for future generations. Growth in any sector is great but if it isn't sustainable then there are least chances to see a prosperous future. Saving energy somehow implies saving the environment. The energy sources are extracted from the environment and can be conserved for future generations if the environment is rescued from degrading. Environmental degradation is a serious obstruction in sustainable energy development. Moreover, it is predicted that we may see a fall in the number of fossil fuels that are profitably extracted. Therefore, the objective to save, more and more energy for the future and reduce the use of fossil fuel consumption is of great significance. The road to energy sustainability through the smart grid is unlocked by 2 major initiatives, viz;

1. BRINGING DOWN THE USE OF FOSSIL FUELS ON THE GENERATION SIDE IN THE POWER GRID

A substantial threat to the environment and thus to sustainable development is the use of fossil fuels. Fossil fuels are carbon-based materials and their combustion results in the emission of carbon dioxide (CO2). Thus, by utilizing fossil fuels as the primary source for power generation, traditional grids contribute to the $\mathrm{CO} 2$ emission that is a principal greenhouse gas. Carbon dioxide $\mathrm{CO} 2$ emitted by various sources is responsible for heattrapping, leading to global warming and climate change. In actual fact, about $40 \%$ of $\mathrm{CO} 2$ is emitted during power generation through traditional power grids, thus we need to adopt a more environmentfriendly infrastructure for the power grid that is put forth through the innovation of SMART GRIDS. Amid the energy crisis, the development of a smart grid can play a vital role in stimulating energy sustainability. By introducing smart grid technology in the power system we can certainly reduce $\mathrm{CO} 2$ emissions. The smart grid also encourages the use of electric vehicles that would result in lower dependency on fossil fuels and thus a reduction in greenhouse gas emissions.

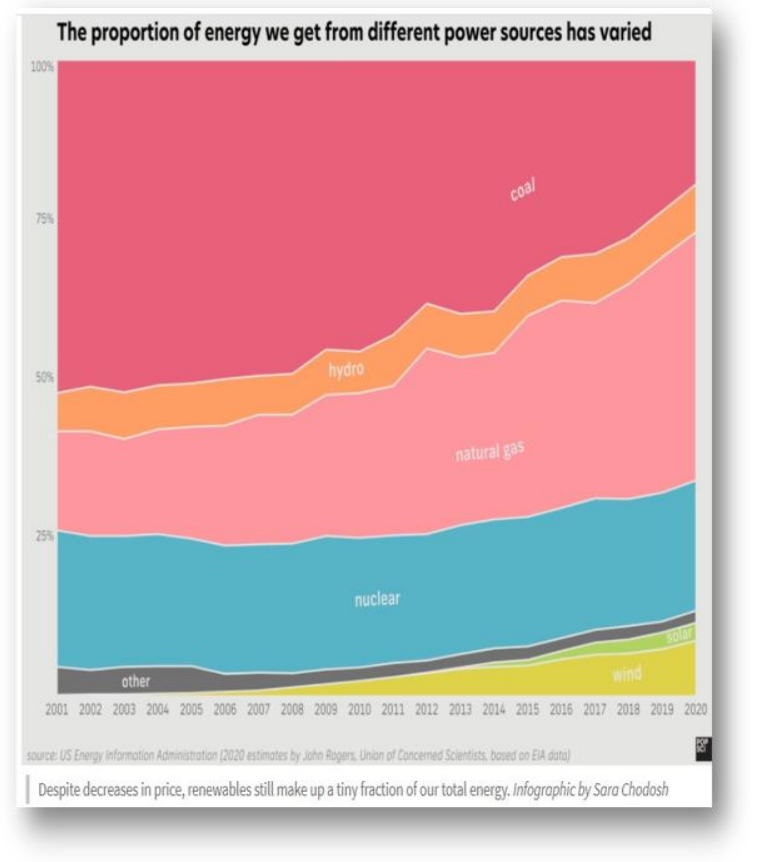

Fig 3:Energy production from different sources 


\section{SWITCHING TO GREEN ENERGY FOR POWER GENERATION}

Energy conservation and environmental conservation are somewhat interlinked. The electric energy delivered to our homes or industries is a secondary source of energy because it is generated by the conversion of primary sources of energy i.e. coal, petroleum, natural gas, solar energy, wind energy, etc. The electric power generation by the burning of fossil fuels like coal, petroleum, natural gas is not a sustainable option as we can run out of fossil fuels anytime. The world has witnessed an immense drop in the quantity of fossil fuels. Thus, the world is undergoing a paradigm shift in the utilization of energy from fossil fuels to using green energy sources that are environment-friendly. This shift is also observed in the power sector. With the advent of smart grid technology the power generation using clean renewable sources has become much easier. The utilization of renewable sources is possible only when there is a feasible infrastructure that matches the variable nature of energy sources. For instance, Solar or Wind energy is highly variable as they depend on SUN and WIND respectively, but electricity demands are not variable, there is always a need for an uninterrupted power supply. So a manageable system is put forth by SMART GRID. Smart grids can incorporate the following characteristics;

- Smart grid integrates the wide range of green renewable energy sources and ensures that demand is always equal to supply. for example, if a photovoltaic (PV) system output drops due to a cloud, then the smart grid interrupts the electricity supply without any penalty and restores the services once the cloud has moved on.

- Smart grid promotes DISTRIBUTED RENEWABLE GENERATION, i.e power generation at a small scale usually through privately-owned power plants. This is contrary to the traditional electric grids that find it difficult to integrate distributed generation with the grids due to operating and stability issues and difficulty in pricing the generation.

- Another major challenge faced in the utilization of green renewable energies is the capital required for installation. Renewable energy technologies have high installation costs but are cost-efficient on a lifecycle basis. Smart grid brings a solution for this problem by involving private investors in electricity generation. Unlike traditional grids, Smart grids don't take the responsibility of building power plants but instead include many small-scale individually owned power plants in the electricity generation system. All in all the smart grid paves a way for the utilization of green renewable energy sources thus aiming for an environment-friendly and energy sustainable future.

\section{CONCLUSION}

This paper discusses thoroughly that SMART GRID is an advanced and emerging technology in the power system that plays a vital role in incorporating energy efficiency in the power sector and supporting a sustainable energy future. The transition from traditional grids to smart grids is mostly hindered by the initial capital and investments required in the installation of entirely new infrastructure and replacing the existing power grids. Nevertheless, as the past has witnessed, every innovation in its initial stages faces an apathetic response but as it reaches its absolute stage the world recognizes its contribution. So is the case with a smart grid as it would achieve its ultimate goal of making a NATIONAL SMART GRID, its contribution will be visible in relieving the pressure on energy demand. This paper is a small effort to highlight the predominant role of the smart grid in improving energy efficiency and sustaining energy for the future amid the energy crisis.

\section{REFERENCES}

1 Frances Brazier, Frank Cornelissen, Rune Gustavsson , Catholijn M. Jonker, Olle Lindeberg, Bianca Polak, Jan Treur, "Agents Negotiating for Load Balancing of Electricity Use", Proceedings, 18th International Conference on Distributed Computing System, IEEE, Amsterdam, Netherlands, pp.622- 629, May, 1998.

2 K.P.Wong, A. Li. and T.M.Y. Law, "Advanced Constrained Genetic Algorithm Load Flow Method", IEEE- ProceedingsGeneration, Transmission and Distribution, vol. 146, no. 6, pp. 609-616, Nov, 1999.

3 S. Li., K. Tomsovic, T. Hiyama, "Load Following Functions Using Distributed Energy Resources", 2000 Power Engineering Society Summer Meeting, IEEE, Seattle, WA, USA, pp. 1756- 1761, July, 2000.

4 T. Amakasu, "Power Technology Development Schemes for the Deregulated Electrical Power Industry", DRPT 2000. International Conference on Electric Utility Deregulation and Restructuring and Power Technologies. Proceedings, London, UK, pp. xviii-xxii, April, 2000.

5 K. Okuyama, T. Kato, Kai Wu, Y. Yokomizu, T. Okamoto, Yasuo Suzuoki, "Improvement of Reliability of Power Distribution System by Information Exchange Between Dispersed Generators", IEEE Power Engineering Society Winter Meeting Conference :Proceedings, Columbus, USA, pp. 741- 746, Feb, 2001.

6 Yaw-Juen Wang, L. Pierrat, "A Method Integrating Deterministic and Stochastic 
Approaches for The Simulation of Voltage Unbalance in Electric Power Distribution System", IEEE Transactions on Power System, vol. 16, no.2, pp. 241-246, May, 2001.

7 D. Laforenza, "Grid programming: some indications where we are headed", Parallel Computing, vol. 28. no.12, pp.1733-1752, Dec 2002.

8 Aravind, C.V., Norhisam, M., Suresh, K.M., Ramesh, G.P. "Assessment on the harnessing of the energy from the back pressure chamber of palm oil mill" (2015) Journal of Engineering Science and Technology, 10 (Spec.issue8), pp. 46- 56.

9 Jian Zhang, Hongchi Shi, "Energy-Efficient Routing for 2D Grid Wireless Sensor Networks", International Conference on Information Technology: Research and Education, 2003. Proceedings, Newark, New Jersey, USA, pp. 311315, August, 2003.

10 J. Heyen, Thomas v. Kerssenbrock, A. Chernyakov, P. Heide, A. F. Jacob, "Novel LTCCBGA-Modules for Highly Integrated MillimeterWave Transceivers", IEEE MTT-S International Microwave Symposium Digest, Philadelphia, PA, USA, pp. 1041-1044, June, 2003.

11 A. Zaia, Dario Bruneo, Antonio Puliafito, "A Scalable Gridbased Multimedia Serve", 13th IEEE International Workshops on Enabling Technologies: Infrastructure for Collaborative Enterprises, Modena, Italy, June, 2004.

12 A. Assal, V. Groza, "Agent-based Resource Management for Smart Robotic Sensors", Canadian Conference on Electrical and Computer Engineering, IEEE, Niagara Falls, Ontario, Canada, pp. 2239-2242, May, 2004. 13 A. Malozemoff, B. Kehrli, J. Diazdeleon, S. Kalsi, "Superconducting Technologies for a Controllable and Reliable High Capacity Grid", IEEE Power Engineering Society General Meeting, Denver, CO, USA, June, 2004.

14 M Siddiqui, Alex Villazon, Radu Prodan, Thomas Fahringer, "Advanced Reservation and Co-Allocation of Grid Resources: A Step towards an invisible Grid", Pakistan Section Multitopic Conference, Karachi, Pakistan, pp. 1-6, December, 2005.

15 Theewara Vorakosit, P. Uthayopas, "Designing an Efficient Simulation Tool for MPI Runtime Algorithm on Grid", 5th International Conference on Information Communications \& Signal Processing, Bangkok, Thailand, pp. 1249-1253, December, 2005.

16 K. Limaye, B. Leangsuksun, V. K. Munganuru, Z. Greenwood, S. L. Scott, R. Libby, K. Chanchio, "Grid Aware HA-OSCAR", 19th International Symposium on High Performance Computing Systems and Applications, Guelph, ON, Canada, pp. 333-339, May, 2005.

17 L. Gertmar, P. Karlsson, O. Samuelsson, “On DC Injection to AC Grids from Distributed
Generation", European Conference on Power Electronics and Applications, IEEE, Dresden, Germany, pp. 1-10, September, 2005.

18 R. F. Sari, R. Paulus, "An Experience in Accessing Grid Computing Power from Mobile Device with Grid Lab Mobile Services", International Conference on Computing \& Informatics, Kuala Lumpur, Malaysia, June, 2006.

19 D. Kouril, L. Matyska, M. Prochazka, "Improving Security in Grids Using the Smart Card Technology", 7th IEEE/ACM International Conference on grid computing, Barcelona, Spain, pp. 303-304, September, 2006.

20 J. Hughes, "IntelliGrid Architecture Concepts and IEC61850", IEEE/PES Transmission and Distribution Conference and Exhibition, Dallas, TX, USA, pp. 401-404, May, 2006.

21 A. Pasdar, S. Mirzakuchaki, "A Solution to Remote Detecting of Illegal Electricity Usage Based on Smart Metering", 2nd International Workshop on Soft Computing Applications, Oradea, Romania, pp.163-167, August, 2007. 22 Yi Yang, Frank Lambert, Deepak Divan, "A Survey on Technologies for Implementing Sensor Networks for Power Delivery Systems", IEEE Power Engineering Society General Meeting, Tampa, FL, USA, pp. 1-8, June, 2007. 23 M.P.F. Hommelberg, C. J. Warmer, I. G. Kamphuis, J. K. Kok, G. J. Schaeffer, "Distributed Control Concepts using MultiAgent technology and Automatic Markets: An indispensable feature of smart power grids", IEEE Power Engineering Society General Meeting, Tampa, FL, USA, pp. 17, June, 2007.

24 Maarten J.C. Berende, J. Kuiper, J. G. Slootweg, J. C. F. M. Peters, "Asset Management Arguments for Smart Grids”, CIRED Seminar 2008: Smart Grids for Distribution, IET, Frankfurt, Germany, pp. 1-4, June, 2008.

25 A. K. Shah, S. Chowdhury, S. P. Chowdhury, P.A. Corssley, "Microturbine Based Distributed Generator in Smart Grid Application", CIRED Seminar 2008: Smart Grids for Distribution, IET, Frankfurt, Germany, pp. 1-4, June, 2008.

26 C. Bennett, D. Highfill, "Networking AMI Smart Meters", IEEE Energy 2030 Conference, Atlanta, GA, USA, pp. 1-8, November, 2008.

27 Ittetsu Taniguchi, Keita Kojima, Masahiro Fukui, "A Practical Battery Charge/Discharge Simulator for Future Embedded Systems including Smart Grids", International SoC Design Conference, IEEE, Busan, South Korea, pp. 173176, November, 2009.

28 Sioe T. Mak, "A Synergistic Approach to Implement Demand Response, Asset Management and Service Reliability Using Smart Metering, AMI and MDM Systems", IEEE Power \& Energy Society General Meeting, Calgary, AB, Canada, pp. 1-4, July, 2009. 